\title{
Tetiva mišića plantarisa - novi presadak i operacijska tehnika zajedničke rekonstrukcije prednjeg križnog i anterolateralnog ligamenta koljena
}

\section{Plantaris muscle tendon - a novel graft in new operation technique for combined anterior cruciate and anterolateral ligament reconstruction of the knee}

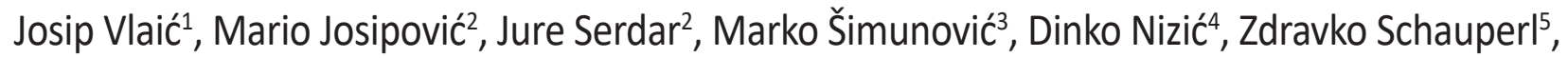
Mislav Jelić6 ${ }^{*}$

${ }^{1}$ Zavod za dječju ortopediju, Klinika za dječje bolesti Zagreb, Zagreb

${ }^{2}$ Klinika za ortopediju KBC-a Zagreb, Zagreb

${ }^{3}$ Klinika za radiologiju KBC-a Zagreb, Zagreb

${ }^{4}$ Zavod za radiologiju i ultrazvučnu dijagnostiku, Specijalna bolnica za plućne bolesti, Zagreb, Zagreb

${ }^{5}$ Zavod za materijale, Fakultet strojarstva i brodogradnje Sveučilišta u Zagrebu, Zagreb

${ }^{6}$ Klinika za ortopediju KBC-a Zagreb,

Medicinski fakultet Sveučilišta u Zagrebu, Zagreb

\section{"Dopisni autor:}

Prof. dr. sc. Mislav Jelić, dr. med., Klinika za ortopediju KBC-a Zagreb, Medicinski fakultet Sveučilišta u Zagrebu Šalata 6-7, 10000 Zagreb E-mail: mislavorto@gmail.com
Sažetak. Mišić plantaris je mali mišić površnog stražnjeg odjeljka noge karakteriziran najdužom tetivom u ljudskom tijelu. Istraživanja ukazuju da je plantaris rudimentarni mišić sa zanemarivom biomehaničkom funkcijom. Tetiva mišića plantarisa odavno je prepoznata kao lako dostupan presadak kod raznih rekonstruktivnih zahvata u ortopediji. Anterolateralni ligament koljena predstavlja važan čimbenik uspostave rotacijske stabilnosti kod koljena kojem nedostaje funkcija prednjeg križnog ligamenta. Tetiva mišića plantarisa ima odlična biomehanička svojstva za rekonstrukciju anterolateralnog ligamenta. U ovom kratkom preglednom radu prikazana je nova operacijska tehnika zajedničke rekonstrukcije prednjeg križnog ligamenta i anterolateralnog ligamenta koljena uz presatke tetiva mišića semitendinozusa i plantarisa.

Ključne riječi: anterolateralni ligament; koljeno; mišić plantaris; presadak tetive plantarisa; rekonstrukcija ligamenata

Abstract. Plantaris muscle is a fusiform muscle of the superficial posterior leg compartment. It is characterized by the longest tendon in humans. Reports suggest that plantaris muscle is rudimentary with a minor biomechanical function. Plantaris tendon is a well known and accessible graft for various reconstructive procedures. The anterolateral ligament has recently been recognized as an important structure in restoring the rotational stability of the anterior cruciate ligament deficient knee. Plantaris tendon has excellent biomechanical properties for anterolateral ligament reconstruction. The present study describes a new combined anterior cruciate ligament and anterolateral ligament reconstruction technique using plantaris tendon and semitendinosus tendon

Key words: anterolateral ligament; knee; ligament reconstruction; plantaris muscle; plantaris tendon graft

http://hrcak.srce.hr/medicina 


\section{UVOD}

Mišić plantaris (lat. musculus plantaris, PL) mali je i fuziformni mišić površnog stražnjeg odjeljka noge karakteriziran najdužom tetivom u ljudskom tijelu ${ }^{1}$. Zbog svojih anatomskih i fizioloških značajki smatra se rudimentarnim mišićem $s$ beznačajnim utjecajem na biomehaniku koljena i gležnja. No, literatura navodi njegovu proprioceptivnu funkciju i klinički značaj kod pojave bolnosti stražnjeg dijela potkoljenice ${ }^{2,3}$. Isto tako, skoro jedno stoljeće različite su kirurške profesije prepoznale korisnost tetive mišića plantarisa (PL) kao vrijednog presatka kod raznih rekonstruktivnih zahvata ${ }^{4-6}$.

Samostalna rekonstrukcija prednjeg križnog ligamenta (engl. anterior cruciate ligament, $\mathrm{ACL}$ ) koljena kod simptomatskih pacijenata ne može uvijek vratiti normalnu kinematiku koljena, bez obzira na korištenu tehniku rekonstrukcije ${ }^{7}$. Stoga je u posljednje vrijeme prepoznata uloga anterolateralnog ligamenta (engl. anterolateral ligament, ALL) koljena kao važnog činitelja rotacijske stabilnosti koljena te je opisano više tehnika njegove rekonstrukcije ${ }^{8,9}$.

$\mathrm{U}$ ovom kratkom pregledom radu opisujemo PL i predstavljamo tetivu PL-a kao novi presadak kod rekonstrukcije ALL-a koljena. Također će biti prikazana, nedavno opisana, operacijska tehnika rekonstrukcije ALL-a uz pojačanje presatka ACL-a tetivom PL-a kod njihove zajedničke rekonstrukci$\mathrm{je}^{10}$.

\section{MIŠIĆ PLANTARIS}

\section{Evolucija, anatomija i fiziologija mišića plantarisa}

PL ili tabanski mišić mali je vretenasti mišić na stražnjem dijelu potkoljenice karakterističan zbog kratkog mišićnog trbuha i jako vitke i dugačke tetive. $\mathrm{Na}$ proksimalnom dijelu potkoljenice je smješten između mišića gastroknemijusa i popliteusa, dok se distalno nalazi između mišića gastroknemijusa i soleusa ${ }^{11}$. PL topografski pripada površinskom sloju mišića stražnjeg odjeljka potkoljenice. Neki autori opisuju PL kao samostalan mišić, dok drugi opisuju PL s mišićima gastroknemijusom i soleusom koji zajedno čine mišić triceps potkoljenice (lat. musculus triceps surae $)^{2,11-13}$.
Kroz evoluciju uspravnog stava čovjeka i usporedbom anatomskih i funkcionalnih razlika među vrstama te, konačno, proučavanjem karakterističnog izgleda PL-a kod čovjeka, u literaturi je opisano nekoliko teorija njegova razvoja ${ }^{6}$. Smatra se kako je razvojem uspravnog stava čovjeka PL postao rudimentaran zato što se njegovo distalno hvatište premjestilo $s$ plantarne aponeuroze na petnu kost ${ }^{14}$. $\mathrm{S}$ obzirom na to da je kroz proces evolucije stopalo čovjeka postalo organ za oslanjanje o podlogu, plantarna aponeuroza postu-

Mišić plantaris ima najdužu tetivu u ljudskom tijelu koja se do sada kao presadak koristila kod raznih rekonstruktivnih zahvata. Oduzimanje tetive mišića plantarisa gotovo je beznačajno za biomehaniku koljena. Prema dosadašnjim istraživanjima, presadak dvostruko presavijene tetive mišića plantarisa ima veću maksimalnu silu od nativnog anterolateralnog ligamenta koljena.

pno je razvijala hvatište na donjoj strani petne kosti, dok je mišićni dio plantarne aponeuroze na potkoljenici regredirao ${ }^{15}$. Za razliku od ljudi, distalno hvatište PL-a se kod nekih sisavaca, primata ili američkog mrkog medvjeda nalazi na plantarnoj aponeurozi i ima funkciju te pomaže kod hvata stopalom ${ }^{15-17}$.

Uredno razvijen $\mathrm{PL}$ ima proksimalno hvatište na lateralnoj suprakondilarnoj liniji femura, proksimalno i medijalno od hvatišta lateralne glave gastroknemijusa i djelomično s kosog popliteanog ligamenta ${ }^{3,18}$. Od svog polazišta PL ide prema distalno i medijalno preko poplitealne udubine tako da se trbuh PL-a nalazi iza poplitealnog mišića i ispred lateralne glave gastroknemijusa, a tetivno-mišićni spoj obično u visini polazišta mišića soleusa ${ }^{1,18}$. Tetiva PL dominatno se nastavlja $\mathrm{s}$ medijalne strane trbuha mišića i ide prema dolje između medijalne glave mišića gastroknemijusa i soleusa ${ }^{19}$.

Njegova tetiva iznimno je dugačka, tanka, spljoštena i proporcionalna je duljini tibije. Uobičajena duljina je tri do četiri puta viša od duljine trbuha PL-a te se smatra najduljom tetivom u čovjeka ${ }^{1}$. Štoviše, zbog velike duljine i tankog oblika tetive PL-a neiskusni se studenti medicine za vrijeme anatomske disekcije potkoljenice mogu za- 
buniti i pogriješiti te tetivu proglasiti živcem. Stoga postoje neformalni nazivi za PL, kao živac početnika (engl. freshman's nerve) ili živac budala (engl. fool's nerve) ${ }^{20}$.

$\mathrm{U}$ distalnoj trećini potkoljenice tetiva PL-a ide uz medijalnu stranu Ahilove tetive do svog hvatišta na petnu kost (lat. os calcaneus), međutim, hvatište tetive PL-a nije stalno i podložno je promjenama, pa su tako u literaturi do sada opisana hvatišta tetive PL-a za sve susjedne strukture kuda prolazi ${ }^{15}$. Na odrasloj populaciji provedena istraživanja dostupnosti PL-a ukazuju da on nedostaje u 6,7 do $19 \%$ udova, pa su i time neki autori zaključili da je PL nerazvijen i rudimentaran mišić15,21-24. No, druga anatomska istraživanja pronašla su PL u 98 do $100 \%$ udova ${ }^{25,26}$. Zaključno se ne može do kraja jasno utvrditi je li PL rudimentaran mišić ili nije te će u budućnosti biti potrebno provoditi dodatna istraživanja da se točno utvrdi njegova postojanost ${ }^{6,27}$.

PL ima dva izvora krvne opskrbe, površinski sloj mišića dobiva krvnu opskrbu iz lateralne suralne i poplitealne arterije dok duboki sloj dobiva krvnu opskrbu iz gornje lateralne arterije koljena ${ }^{1}$. Tetivu PL-a opskrbljuje stražnja tibijalna arterija, a isto kao mišiće soleus i gastroknemijus, PL inervira tibijalni živac (korijeni S1 i S2) ${ }^{28,29}$. S biomehaničkog gledišta, PL je dvozglobni mišić koji pridonosi fleksiji koljena i plantarnoj fleksiji gležnja ${ }^{30}$. S obzirom na to da je gastroknemijus značajno veći i jači mišić od PL-a te sudjeluje $u$ istim pokretima koljena i gležnja, smatra se da je do- prinos PL-a kod fleksije koljena i plantarne fleksije gležnja neznatan (npr. PL pridonosi 0,7 \% snage plantarne fleksije gležnja) ${ }^{12,31}$. Vjeruje se, međutim, da PL ima izraženu proprioceptivnu ulogu zbog povišene gustoće mišićnih vretena te slanjem aferentnih informacija o položaju stopala središnjem živčanom sustavu, PL zapravo pomaže aktivnosti jačih plantarnih fleksora gležnja ${ }^{12,20,32}$.

\section{Klinički značaj mišića plantarisa}

PL ima svoju kliničku važnost kod pojave bolnosti stražnjeg dijela potkoljenice ${ }^{2,3}$. Značajno odstupanje $u$ anatomiji PL-a prijavili su Kwon i sur. navodeći da previše medijalno i proksimalno položen trbuh PL-a u forsiranoj plantarnoj fleksiji stopala uzrokuje kompresivni sindrom poplitealne arterije (engl. popliteal artery entrapment syndrome $\mathrm{PAES}^{33}$. Kao što je ranije opisano, tetiva PL-a je u jako bliskom odnosu s Ahilovom tetivom te joj ponekad služi i kao distalno hvatište ${ }^{26}$. Patogeneza neinsercijske tendinopatije Ahilove tetive nije još do kraja razjašnjena, međutim, vjeruje se da odstranjenje zadebljane tetive PL-a može imati pozitivan učinak na proces oporavka Ahilove tetive ${ }^{34}$. Puknuće PL-a, što je zasebni klinički entitet, može uzrokovati akutnu bolnost u stražnjem dijelu potkoljenice $^{35}$. Ranije se vjerovalo da je uzrok tzv. teniske potkoljenice puknuće PL-a, međutim, danas se smatra da je uzrokuje ozljeda medijalne glave gastroknemijusa ${ }^{3}$.

Vrlo brza, jeftina i pouzdana metoda određivanja razlike između puknuća PL-a i gastroknemijusa je

Tablica 1. Rekonstruktivni postupci gdje se primijenio autologni tetivni presadak mišića plantarisa

\begin{tabular}{|l|l|}
\hline \multicolumn{1}{|c|}{ Regija } & \multicolumn{1}{c|}{ Postupak } \\
\hline Glava & Plastične operacije na licu nakon paralize ličnog živca ${ }^{40}$ \\
\hline Rame & Rekonstrukcija korakoklavikularnog ligamenta ${ }^{4}$ \\
\hline Prsa & Stabilizacija stražnjeg sternoklavikularnog iščašenja ${ }^{41}$ \\
\hline Podlaktica & Rekonstrukcija tetiva dubokih pregibača šake ${ }^{42}$ \\
\hline Šaka & Rekonstrukcija tetiva pregibača prstiju ${ }^{43}$ \\
\hline Trbuh & Popravak ingvinalne hernije ${ }^{44}$ \\
\hline Koljeno & Rekonstrukcija ligamenta patele ${ }^{5}$ \\
\hline Koljeno & Rekonstrukcija anterolateralnog ligamenta ${ }^{10}$ \\
\hline Gležanj & Rekonstrukcija ligamenata gležnja ${ }^{45,46}$ \\
\hline Glažanj & Rekonstrukcija peronealnog retinakula ${ }^{47}$ \\
\hline Gležanj & Popravak tetive dugog peroneusa ${ }^{48}$ \\
\hline Gležanj & Rekonstrukcija Ahilove tetive ${ }^{49}$ \\
\hline
\end{tabular}


upotreba ultrazvuka, zajedno s kliničkim pregledom $^{36}$. Puknuće PL-a dogodi se uglavnom indirektnim mehanizmom, bez određene traume $u$ podlozi ${ }^{36}$. Najčešće se puknuće PL-a dogodi kod trčanja i skakanja, kada je stopalo u dorzifleksiji, a koljeno u punoj ekstenziji, jer je tada PL pod ekscentričnim opterećenjem zbog istovremene aktivne kontrakcije i pasivnog istezanja ${ }^{12,37,38}$.

Puknuće PL-a može se klinički prezentirati kao medicinska hitnoća zbog krvarenja i otekline te može nastati sindrom fascijalnog odjeljka, što treba prepoznati i liječiti na vrijeme ${ }^{39}$. Druge smetnje u regiji potkoljenice, kao npr. duboka venska tromboza, puknuće Bakerove ciste ili tumor treba znati razlikovati od puknuća PL-a ${ }^{39}$.

\section{Mišić plantaris kao presadak u rekonstruktivnoj kirurgiji}

Unatrag devedeset godina razne kirurške struke prepoznale su korisnost PL-a, točnije, njegove tetive za upotrebu kao slobodni tetivni presadak kod raznih rekonstruktivnih postupaka ${ }^{4,5}$. Tablica 1 prikazuje anatomske lokalizacije i navodi postupke kada se koristio autologni tetivni presadak PL-a $a^{4,5,10,40-49}$. Valja naglasiti da je rekonstrukcija ALL-a posljednja prijavljena upotreba tetive PL-a kao autolognog tetivnog presatka, te će kasnije biti detaljno opisana ${ }^{10}$. Glavni razlog učestale primjene presatka tetive PL-a je jednostavna tehnika uzimanja i izostanak morbiditeta donorskog mjesta ${ }^{46}$. Tetiva PL-a može se uzeti, relativno sigurno, proksimalnim i distalnim pristupom. Zbog opisanih anatomskih varijacija distalnog hvatišta PL-a u regiji gležnja, danas se ipak preporučuje uzimati tetivu PL-a proksimalnim pristupom jer se proksimalni način uzimanja tetive PL-a pokazao kao manje invazivan i s minimalnim posljedicama $^{46}$. lako se autologni tetivni presadak PL-a do sada višestruko upotrebljavao kod raznih popra- vaka i rekonstrukcija, biomehanička svojstva jednostruke tetive PL-a nisu previše istraživana ${ }^{50-52}$. U svim do sada provedenim istraživanjima tetive $i$ tetivni uzorci nisu bili testirani na potpuno isti način, nego na sličan, što može predstavljati ograničenja kod usporedbe rezultata i njihove interpretacije. No, presadak jednostruke cijele tetive PL-a ili samo uzorak jednostruke tetive PL-a pokazao je usporedive vrijednosti srednje maksimalne sile kod tri prethodna biomehanička ispitivanja. Tako je srednja maksimalna sila presatka jednostrukog uzorka ili tetive PL-a dobivena $\mathrm{u}$ radu Walker i sur. bila 165,3 $\mathrm{N}$ (raspon od 123,4 do 245,9 ), u radu Zarzycki i sur. 161,5 N ( $\pm 24,4$ std) i Bohnsack i sur. 196,9 N (raspon od 244 do $246)^{50-52}$.

\section{NOVA OPERACIJSKA TEHNIKA ISTOVREMENE REKONSTRUKCIJE PREDNJEG KRIŽNOG I ANTEROLATERALNOG LIGAMENTA KOLJENA PRESATKOM TETIVE MIŠIĆA PLANTARISA}

\section{Anterolateralni ligament koljena}

Otkako je skupina autora iz Belgije 2013. na kadaveričnim koljenima opisala i imenovala izdvojenu ligamentarnu strukturu koja povezuje lateralni epikondil femura i dio tibije iza Gerdyjeva tuberkula kao ALL, brojna istraživanja kasnije dodatno su pokazala ulogu ALL-a koljena, ${ }^{8,9,53-57}$. Danas se smatra da je glavna uloga ALL-a očuvanje rotacijske stabilnosti neozlijeđenog koljena, ali i koljena kojem nedostaje funkcija ACL-a ${ }^{8,9,57}$. Velik interes za anatomiju i funkciju ALL-a doveo je do provođenja više biomehničkih ispitivanja nativnog ALL-a koja su prijavila njegovu srednju maksimalnu silu oko $180 \mathrm{~N}$ (tablica 2$)^{53-56}$.

Isto tako, u novije vrijeme „oživljene” su neke stare tehnike rekonstrukcije lateralnih ekstrartikularnih struktura koljena, ali su opisane i neke

Tablica 2. Istraživanja biomehaničkih svojstava maksimalne sile nativnog anterolateralnog ligamenta

\begin{tabular}{|l|c|c|}
\hline \multicolumn{1}{|c|}{ Autor istraživanja } & Godina objave istraživanja & $\begin{array}{c}\text { Maksimalna sila (N) } \\
\text { (srednja vrijednost } \pm \text { std) }\end{array}$ \\
\hline Zens M i sur. ${ }^{54}$ & 2015. & $50 \pm 15$ \\
\hline Kennedy Ml i sur. ${ }^{53}$ & 2015. & $175 \pm 65$ \\
\hline Wytrykowski K i sur. $^{56}$ & 2016. & $141 \pm 41$ \\
\hline Helito CP i sur. ${ }^{55}$ & 2016. & $205 \pm 115$ \\
\hline N = Newton; std $=$ standardna devijacija & & \\
\hline
\end{tabular}




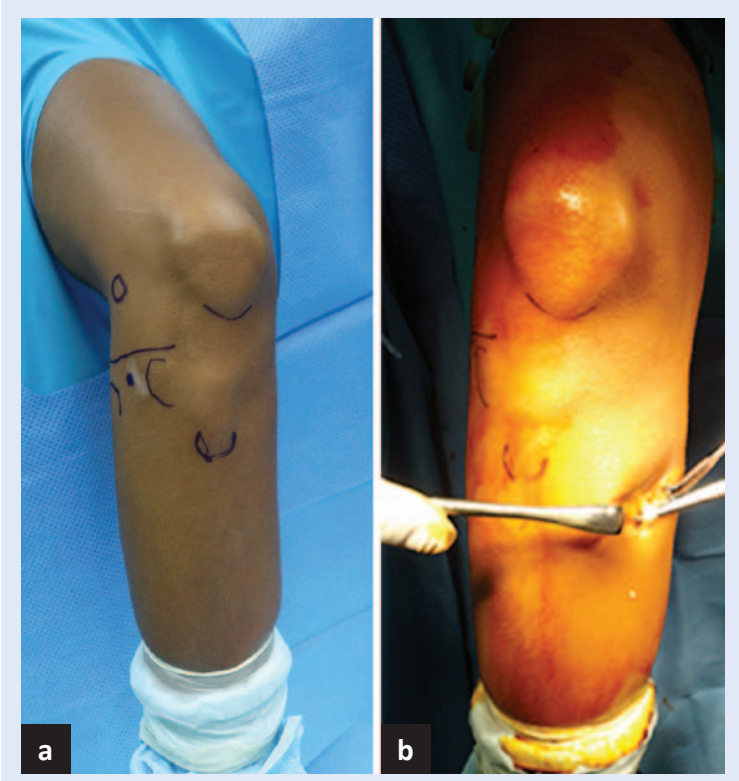

Slika 1. Intaroperativne fotografije: a) Označeni su koštani biljezi, zglobna linija i pozicija anatomskih hvatišta anterolateralnog ligamenta na femuru i tibiji b). Proksimalni pristup za uzimanje tetive mišića plantarisa na medijalnoj strani potkoljenice. Prikazana je tetiva PL-a na kirurškom instrumentu.

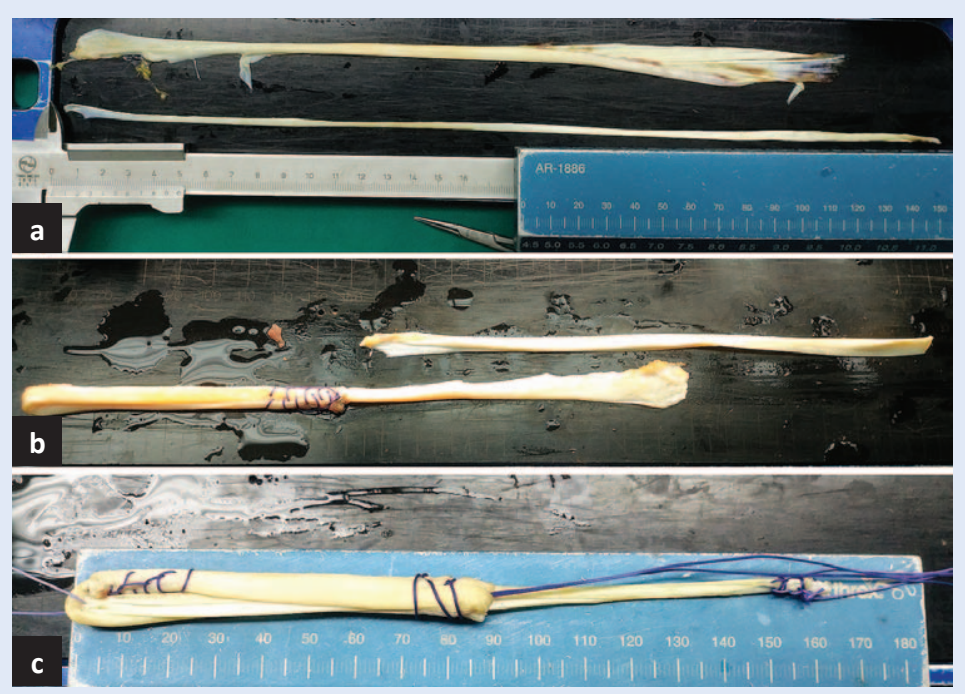

Slika 2. Intaroperativne fotografije. a) pripremljene tetive mišića semitendinozusa i PL-a za izradu presatka; b) dvostruko presavijena tetiva PL-a i tetiva semitendinozusa pripremljena uobičajenim načinom za oblikovanje trostruko presavijenog presatka. Proksimalna trećina tetive semitendinozusa je presavijena na srednju trećinu i prošivena koncima; c) dvostruko presavijena tetiva PL-a postavila se s unutarnje strane pripremljene tetive semitendinozusa, čiji su se krajevi potom presavinuli. Formiran je novi peterostruki presadak za $\mathrm{ACL}$ od trostuko presavijene tetive semitendinozusa i dvostruko presavijene tetive PL-a. Ostatni dio dvostruko presavijene tetive PL-a čini presadak za ALL. (Slika preuzeta iz Josipović i sur. Plantaris tendon: a novel graft for anterolateral ligament reconstruction and additional reinforcement for anterior cruciate ligament autografts in combined reconstructive procedures. Knee Surg Sports Traumatol Arthrosc 2020; Forthcoming) nove tehnike koje rekonstruiraju ALL zajedno s ACL-om. Većina opisanih tehnika koristi presatke tetiva hamstringsa ${ }^{9,57}$. No, posljednja objavljena tehnika zajedničke rekonstrukcije ALL-a i ACL-a, koja će biti opisana u nastavku, kao presadak za rekonstrukciju ALL-a koristi tetivu $\mathrm{PL}-\mathrm{a}^{10}$.

\section{Rekonstrukcija anterolateralnog ligamenta $i$ pojačanje presatka prednjeg križnog ligamenta koljena tetivom mišića plantarisa}

Mišići hamstringsi (semitendinozus i gracilis) agonisti su ACL-a te imaju stabilizacijsku ulogu na koljeno, posebice kod pokreta dinamičkog valgusa, pa se smatra da njihovo oduzimanje za presadak uzrokuje veći rizik za puknuće presatka ACL-a nakon njegove rekonstrukcije ${ }^{58}$. Upravo zbog nepovoljnog učinka na biomehaniku koljena, zbog oduzimanja obje tetive hamstringsa kod rekonstrukcije ACL-a, razvile su se nove tehnike rekonstrukcije ACL-a koje za presadak ACL-a koriste jednu tetivu hamstringsa u trostruko ili četverostruko presavijenom obliku ${ }^{59-61}$. Međutim, s pojavom tehnika zajedničke rekonstrukcije ACL-a i ALL-a potreba za dodatnim presatkom rezultirala je oduzimanjem obje tetive hamstringsa ${ }^{9}$. Stoga su, da bi se izbjegao nepovoljan učinak oduzimanja obje tetive hamstringsa, Josipović i sur. razvili tehniku zajedničke rekonstrukcije ACL-a i ALL-a koljena, koristeći tetivu PL-a kao presadak za $A L{ }^{10}$. Štoviše, kod opisane tehnike tetiva PL-a koristi se i kao pojačanje presatku ACL-a.

Operacijska tehnika izvodi se u položaju pacijenta na leđima, a operirana noga je u držaču i presavijena u koljenu. Koštani biljezi i pozicija anatomskih hvatišta ALL-a na femuru i tibiji označe se na koži lateralne strane koljena. Prema grupi autora iz Lyona, femoralno hvatište ALL-a postavi se proksimalno i straga od lateralnog epikondila (slika 1 a) ${ }^{62}$. Potom se proksimalnim pristupom kroz mali kožni rez iza medijalnog ruba tibije započne oduzimanje tetive PL-a. Učini se rez fascije površnog stražnjeg mišićnog odjeljka potkoljenice te se između mišića gastroknemijusa i soleusa tupim prepariranjem prikaže tetiva PL-a. Tetiva se presječe što proksimalnije i zatvorenim striperom usmjerenim prema distalno odigne sa distalnog hvatišta (slika 1 b) ${ }^{46}$. Tetiva mišića semitendinozusa oduzme se uobičajenim pristupom kroz mali koži rez distalno i medijalno od tuberozitasa tibi- 
je. Peterostruki presadak za ACL se učini od trostruko presavijene tetive mišića semitendinozusa i dvostruko presavijene tetive PL-a, dok se od ostatnog dijela dvostruko presavijene tetive PL-a formira presadak za ALL. Slobodni krajevi presatka prošiju se neresorptivnim koncem (slika 2).

Artroskopija koljena radi se kroz uobičajene ulaze, anterolateralni i anteromedijalni ulaz, te se pripremi femoralno i tibijalno hvatište ACL-a. Zajednički femoralni tunel za ACL i ALL izbuši se tehnikom izvana-unutra koristeći femoralnu vodilicu za rekonstrukciju ACL-a. Preko prethodno postavljene žice vodilice borerom širine pripremljenog presatka izbuši se tunel na femuru, dok se na tibiji učini tunel iste širine uz pomoć tibijalne vodilice. Tunel tibijalnog hvatišta ALL-a pripremi se kroz mali kožni rez između glave fibule i Gerdyjeva tuberkula te $1 \mathrm{~cm}$ distalno od zglobne linije ${ }^{9}$. Žica vodilica usmjeri se anteromedijalno i distalno te se prođe kroz suprotni kortikalis tibije. Potom se preko žice vodilice, borerom od $4,5 \mathrm{~mm}$, učini tunel na tibiji do $3 \mathrm{~cm}$ dužine (slika 3 a i b).

Peterostruki presadak ACL-a se provuče transtibijalno u femoralni tunel, dok se ostatni dio dvostruko presavijene tetive PL-a koji služi kao presadak za ALL izvuče izvan femoralnog tunela. Presadak ACL-a se učvrsti u femoralnom tunelu interferentnim vijkom (Biocomposite Interference Screw, Delta, Arthrex) na vanjskom kortikalisu, pazeći da se ne ošteti presadak ALL-a. Potom se u $20^{\circ}$ do $30^{\circ}$ fleksije koljena i uz potisak tibije prema straga presadak ACL-a učvrsti u tibijalnom tunelu interferentnim vijkom (Biocomposite Interference Screw, Delta, Arthrex). Presadak ALL-a provuče se ispod traktusa iliotibijalisa i provuče u tibijalni tunel uz pomoć ranije pripremljene omče. Koljeno se postavi u položaj pune ekstenzije i presadak ALL-a se na tibijalnom hvatištu pričvrsti interferentnim vijkom (Biocomposite Interference Screw, Arthrex); (slika 3 c i d). Nakon operacije zajedničke rekonstrukcije ACL-a i ALL-a provodi se uobičajena rehabilitacija kao i nakon samostalne rekonstrukcije ACL-a.

Opisanom operacijskom tehnikom izvodi se rekonstrukcija ACL-a i ALL-a koristeći samo jednu od tetiva mišića hamstringsa, presadak tetive mišića semitendinozusa, stoga je glavna prednost ove tehnike što drugi mišić hamstrings, mišić gracilis ostaje sačuvan. Time se biomehanika koljena
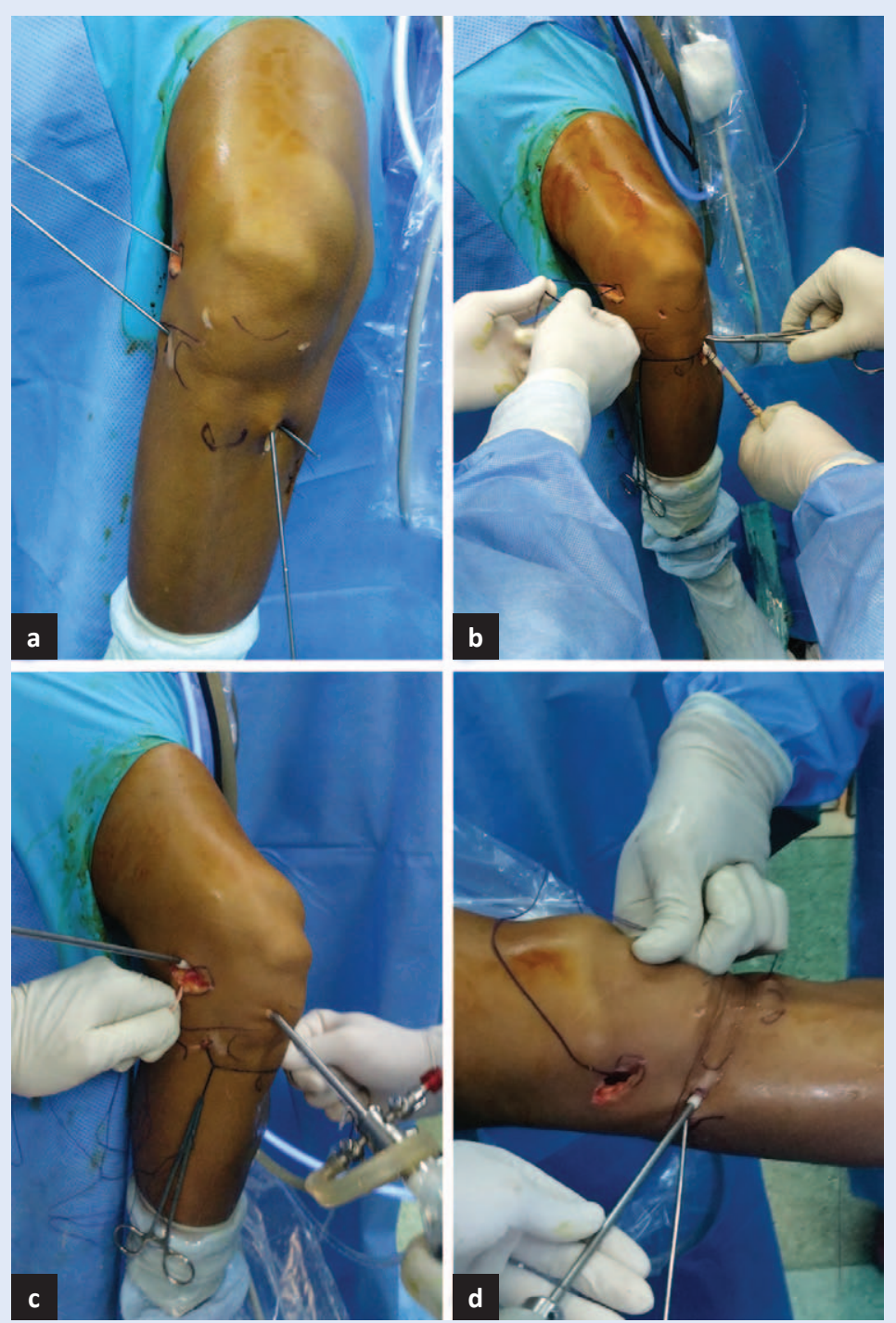

Slika 3. Intaroperativne fotografije. a) žice vodilice postavljene su na mjesto zajedničkog tunela ACL-a i ALL-a na femuru, mjesto tunela ACL-a na tibiji i mjesto tunela ALL-a na tibiji; b) nakon što su svi tuneli izbušeni preko žica vodilica izvana prema unutra, presadak je provučen kroz tunel na tibiji odgovarajućom dužinom u tunel na femuru; c) presadak PL-a za ALL izvučen je van i cijeli presadak je učvršćen interferentnim vijkom na vanjskom kortikalisu femura; d) ostatni dio presatka PL-a za ALL se provuče ispod traktus ilijotibijalisa i punoj ekstenziji koljena pričvrsti na mjestu tunela na tibiji. (Slika preuzeta iz Josipović i sur. Plantaris tendon: a novel graft for anterolateral ligament reconstruction and additional reinforcement for anterior cruciate ligament autografts in combined reconstructive procedures. Knee Surg Sports Traumatol Arthrosc 2020; Forthcoming)

mijenja u manjoj mjeri nego kad se oduzimaju obje tetive hamstringsa, a korišteni presadci ACL-a i ALL-a su zadovoljavajućih biomehaničkih svojstava. Kako je navedeno ranije, prijavljena srednja vrijednost maksimalne sile nativnog ALL-a je oko $180 \mathrm{~N}^{53-56}$. Presadak načinjen od dvostruko presavijene tetive PL-a sigurno ima srednju 
maksimalnu silu veću od potrebne za nadomjestak ALL-a, jer su ranija biomehanička ispitivanja pokazala da jednostruka tetiva PL-a pokazuje srednju maksimalnu silu od 161 do $197 \mathrm{~N}^{50-52}$. Istovremeno, neupitna je dostatnost korištenog presatka trostruko presavijene tetive mišića semitendinozusa za $A C L$, jer se i uobičajeno koristi kod rekonstrukcije ACL-a, a ovom tehnikom je dodatno pojačan dvostruko presavijenom tetivom PL-a. Opisana tehnika, međutim, ima nedostataka. Nedostaci su vezani za PL, a proizlaze iz činje-

Kod nove operacijske tehnike zajedničke rekonstrukcije prednjeg križnog ligamenta $\mathrm{i}$ anterolateralnog ligamenta koljena korištenjem tetive mišića plantarisa; tetiva mišića gracilisa ostaje sačuvana. Presadak mišića plantarisa pojačao je presadak mišića semitendinozusa za prednji križni ligament i nadomjestio anterolateralni ligament koljena. Usporedna klinička ispitivanja u budućnosti pokazat će stvarnu vrijednost opisane operacijske tehnike.

nice da njegova postojanost i razvijenost nije stalna, stoga prije svakog korištenja tetive PL-a za presadak treba učiniti njegovu slikovnu obradu nekim od dostupnih modaliteta oslikavanja ${ }^{27}$. Drugi nedostatak je sama dužina tetive PL-a koja se uspije oduzeti, ako je prekratka onda se ne može koristiti za pojačanje presatka ACL-a. No, ako se ne uspije dobiti dovoljno dužine tetive $\mathrm{PL}-\mathrm{a}$ za pojačanje presatka za $\mathrm{ACL}$, onda se rekonstrukcija ALL-a tetivom PL-a može raditi zasebno.

\section{ZAKLJUČAK}

lako je tetiva PL-a upotrebljavana i ranije kao presadak kod raznih rekonstruktivnih zahvata, njegov presadak za ALL opisan je tek nedavno ${ }^{6,10}$. PL je mišić s neznatnom ulogom u lokomotornom sustavu, stoga njegovo korištenje za presadak ALL-a ne narušava dodatno biomehaniku koljena, kao što to uzrokuje korištenje tetive mišića gracilisa za presadak ALL-a $a^{6,59-61}$. Autori opisani tehnike, a na temelju ranije provedenih biomehaničkih ispitivanja nativnog ALL-a i tetiva PL-a, vjeruju kako dvostruko presavijena tetiva PL-a posjeduje zadovoljavajuća biomehanička svojstva da kao presadak ALL-a osigura rotacijsku stabilnost koljena kod rekonstruk- cije ACL-a ${ }^{10}$. Dodatna usporedna klinička ispitivanja u budućnosti trebala bi pokazati stvarnu vrijednost opisane operacijske tehnike.

Izjava o sukobu interesa: Autori izjavljuju da ne postoji sukob interesa.

\section{LITERATURA}

1. White WL. The unique, accessible and useful plantaris tendon. Plast Reconstr Surg 1960;25:133-41.

2. Menton $\mathrm{D}$. The plantaris and the question of vestigial muscles in man. CEN Tech J 2000;14:50-3.

3. Delgado GJ, Chung CB, Lektrakul N, Azocar P, Botte MJ, Coria $D$ et al. Tennis leg: clinical US study of 141 patients and anatomic investigation of four cadavers with MR imaging and US. Radiology 2002;224:112-9.

4. Gallie WE, Lemesurier AB. The late repair of fractures of the patella and of rupture of the ligamentum patellae and quadriceps tendon. J Bone Joint Surg Am 1927;9:4754.

5. Glissan DJ. The use of the plantaris tendon in certain types of plastic surgery. Aust N Z J Surg 1932;2:64-7.

6. Vlaic J, Josipovic M, Bohacek I, Jelic M. The plantaris muscle: too important to be forgotten. A review of evolution, anatomy, clinical implications and biomechanical properties. J Sports Med Phys Fitness 2019;59:839-45.

7. Paterno MV, Schmitt LC, Ford KR, Rauh MJ, Myer GD, Huang $B$ et al. Biomechanical measures during landing and postural stability predict second anterior cruciate ligament injury after anterior cruciate ligament reconstruction and return to sport. Am J Sports Med 2010; 38:1968-78.

8. Claes S, Vereecke E, Maes M, Victor J, Verdonk P, Bellemans J. Anatomy of the anterolateral ligament of the knee. J Anat 2013;223:321-8.

9. DePhillipo NN, Cinque ME, Chahla J, Geeslin AG, LaPrade RF. Anterolateral ligament reconstruction techniques, biomechanics, and clinical outcomes: a systematic review. Arthroscopy 2017;33:1575-83.

10. Josipović $M$, Vlaić J, Serdar J, Šimunović $M$, Nizić $D$, Schauperl $Z$ et al. Plantaris tendon: a novel graft for anterolateral ligament reconstruction and additional reinforcement for anterior cruciate ligament autografts in combined reconstructive procedures. Knee Surg Sports Traumatol Arthrosc 2020; Forthcoming.

11. Keros P, Pećina M. Funkcijska anatomija lokomotornog sustava. Zagreb: Naklada Ljevak; 2006.

12. Spina AA. The plantaris muscle: anatomy, injury, imaging, and treatment. J Can Chiropr Assoc 2007;51:158-65.

13. Okamoto K, Wakebe T, Saiki K, Tsurumoto T. The nerves to the plantaris muscle and a bipennate part of the soleus muscle. Anat Sci Int 2013;88:17-24.

14. Cruveilhier J. Anatomie Descriptive. Tome II. Paris: Bechet; 1834.

15. Daseler EH, Anson BJ. The plantaris muscle: an anatomical study of 750 specimens. J Bone Joint Surg Am 1943;25:822-7.

16. Le Double AF. Traite des variations du systeme muscularie de l'homme et de leur significantion au point de vue de l'anthropologie zoologique. Tome II. Paris: Schleicher Freres; 1897. 
17. Sawant SP, Shaikh ST, More RM. A rare variation of plantaris muscle. Int J Biol Med Res 2012;3:2437-40.

18. Helms CA, Fritz RC, Garvin GJ. Plantaris muscle injury: evaluation with MR imaging. Radiology 1995;195:201-3.

19. Leekam RN, Agur AM, McKee NH. Using sonography to diagnose injury of plantaris muscles and tendons. AJR Am J Roentgenol 1999;172:185-9.

20. Moore KL, Dalley AR. Clinically oriented anatomy. 6th Edition. Philadelphia: Lippincott Williams and Wilkins; 2008.

21. Harvey JF, Chu G, Harvey PM. Surgical availability of the plantaris tendon. J Hand Surg Am 1983;8:243-7.

22. Wehbe MA. Tendon graft donor sites. J Hand Surg Am 1992;17:1130-2.

23. Simpson SL, Hertzog MS, Barja RH. The plantaris tendon graft: an ultrasound study. J Hand Surg Am 1991;16:70811.

24. Nayak SR, Krishnamurthy A, Ramanathan L, Ranade AV, Prabhu LV, Jiji PJ et al. Anatomy of plantaris muscle: a study in adult Indians. Clin Ter 2010;161:249-52.

25. Saxena A, Bareither D. Magnetic resonance and cadaveric findings of the incidence of plantaris tendon. Foot Ankle Int 2000;21:570-2.

26. van Sterkenburg MN, Kerkhoffs GM, Kleipool RP, van Dijk $\mathrm{CN}$. The plantaris tendon and a potential role in midportion Achilles tendinopathy: an observational anatomical study. J Anat 2011;218:336-41.

27. Vlaić J. Usporedba biomehaničkih svojstava tetiva mišića plantarisa i gracilisa za rekonstrukciju medijalnoga patelofemoralnoga ligamenta. Zagreb: Medicinski fakultet, 2019. PhD thesis.

28. Li Q, Xu J, Zhang D. Vascularized plantaris tendon graft: anatomic study of the donor. J Reconstr Microsurg 2000; 16:287-90.

29. Standring S. Gray's Anatomy: The Anatomical Basis of Clinical Practice. 41th Edition. Philadelphia: Elsevier; 2016.

30. Basmajian JV, De Luca CJ. Muscles alive: their functions revealed by electromyography. Baltimore: Williams \& Wilkins; 1985.

31. Silver RL, de la Garza J, Rang M. The myth of muscle balance. A study of relative strengths and excursions of normal muscles about the foot and ankle. J Bone Joint Surg $\mathrm{Br}$ 1985;67:432-7.

32. Peck D, Buxton DF, Nitz A. A comparison of spindle concentrations in large and small muscles acting in parallel combinations. J Morphology 1984;180:243-52.

33. Kwon YJ, Kwon TW, Um EH, Shin S, Cho YP, Kim JM et al. Anatomical popliteal artery entrapment syndrome caused by an aberrant plantaris muscle. Vasc Specialist Int 2015;3:95-101.

34. Spang C, Alfredson H, Docking SI, Masci L, Andersson G. The plantaris tendon: a narrative review focusing on anatomical features and clinical importance. Bone Joint J 2016;98:1312-9.

35. Pollock N, Dijkstra P, Calder J, Chakraverty R. Plantaris injuries in elite UK track and field athletes over a 4-year period: a retrospective cohort study. Knee Surg Sports Traumatol Arthrosc 2016;24:2287-92.

36. Dar G, Dolev E, Kots E, Cale-Benzoor M. Rehabilitation of plantaris tendon rupture in an elite triathlete: a case report. J Athl Enhancement 2013;2:2.
37. Kwak HS, Han YM, Lee SY, Kim KN, Chung GH. Diagnosis and follow-up US evaluation of ruptures of the medial head of the gastrocnemius ('tennis leg'). Korean J Radiol 2006;7:193-8.

38. Bianchi S, Sailly M, Molini L. Isolated tear of the plantaris tendon: ultrasound and MRI appearance. Skeletal Radiol 2011;40:891-5.

39. Rohilla S, Jain N, Yadav R. Plantaris rupture: why is it important? BMJ Case Rep 2013;22:2013.

40. Yoleri L, Gungor M, Usluer A, Celik D. Tension adjusted multivectorial static suspension with plantaris tendon in facial paralysis. J Craniofac Surg 2013;24:896-9.

41. Aure A, Hetland KR, Rokkum M. Chronic posterior sternoclavicular dislocation. J Orthop Trauma 2012;26:33-5.

42. Jakubietz MG, Jakubietz DF, Gruenert JG, Zahn R, Meffert RH, Jakubietz RG. Adequacy of palmaris longus and plantaris tendons for tendon grafting. J Hand Surg Am 2011;36:695-8.

43. Bertelli JA, Santos MA, Kechele PR, Rost JR, Tacca CP. Flexor tendon grafting using a plantaris tendon with a fragment of attached bone for fixation to the distal phalanx: a preliminary cohort study. J Hand Surg Am 2007; 32:1543-8.

44. Pilcher R. Repair of hernia with plantaris tendon grafts. Arch Surg 1939;38:16-23.

45. Boyer MI, Bowen V, Weiler P. Reconstruction of a severe grinding injury to the medial malleolus and the deltoid ligament of the ankle using a free plantaris tendon graft and vascularized gracilis free muscle transfer: case report. J Trauma 1994;36:454-7.

46. Pagenstert GI, Hintermann B. Proximal mini-invasive grafting of plantaris tendon In: Easley ME, Wiesel SW, Editors. Operative Techniques in Foot and Ankle Surgery. Philadelphia: Lippincott Williams \& Wilkins, a Wolters Kluwer business; 2011;973-7.

47. Hansen $\mathrm{BH}$. Reconstruction of the peroneal retinaculum using the plantaris tendon: a case report. Scand J Med Sci Sports 1996;6:355-8.

48. Sammarco GJ. Peroneus longus tendon tears: acute and chronic. Foot Ankle Int 1995;16:245-3.

49. Sadek AF, Fouly EH, Laklok MA, Amin MF. Functional and MRI follow-up after reconstruction of chronic ruptures of the Achilles tendon Myerson type III using the tripleloop plantaris tendon wrapped with central turndown flap: a case series. J Orthop Surg Res 2015;10:109.

50. Walker LB, Harris EH, Benedict JV. Stress-strain relationship in human cadaveric plantaris tendon: a preliminary study. Med Electron Biol Eng 1964;2:31-8.

51. Zarzycki W, Mazurkiewicz S, Wisniewski P. Research on strength of the grafts that are used in anterior cruciate ligament reconstruction. Pol Orthop Traumatol 1999;64: 293-302.

52. Bohnsack M, Surie B, Kirsch IL, Wulker N. Biomechanical properties of commonly used autogenous transplants in the surgical treatment of chronic lateral ankle instability. Foot Ankle Int 2002;23:661-4.

53. Kennedy MI, Claes S, Fuso FA, Williams BT, Goldsmith MT, Turnbull TL et al. The anterolateral ligament: an anatomic, radiographic, and biomechanical analysis. Am J Sports Med 2015;43:1606-15.

54. Zens M, Feucht MJ, Ruhhammer J, Bernstein A, Mayr HO, Sudkamp NP et al. Mechanical tensile properties of the anterolateral ligament. J Exp Orthop 2015;2:7. 
55. Helito CP, Bonadio MB, Rozas JS, Wey JMP, Pereira CAM, Cardoso TP et al. Biomechanical study of strength and stiffness of the knee anterolateral ligament. BMC Musculoskel Disord 2016;17:193.

56. Wytrykowski K, Swider P, Reina N, Murgier J, Laffosse JM, Chiron $\mathrm{P}$ et al. Cadaveric study comparing the biomechanical properties of grafts used for knee anterolateral ligament reconstruction. Arthroscopy 2016;32:2288-94.

57. Sonnery-Cottet B, Daggett M, Fayard JM, Ferretti A, Helito $\mathrm{CP}$, Lind $\mathrm{M}$. et al. Anterolateral Ligament Expert Group consensus paper on the management of internal rotation and instability of the anterior cruciate ligamentdeficient knee. J Orthop Traumatol 2017;18:91-106.

58. Cerulli G, Placella G, Sebastiani E, Tei MM, Speziali A, Manfreda F. ACL reconstruction: choosing the graft. Joints 2013; 1:18.
59. Liu W, Maitland ME. The effect of hamstring muscle compensation for anterior laxity in the ACL-deficient knee during gait. J Biomech 2000;33:871-79.

60. Zamarra G, Fisher MB, Woo SL, Cerulli G. Biomechanical evaluation of using one hamstrings tendon for $A C L$ reconstruction: a human cadaveric study. Knee Surg Sports Traumatol Arthrosc 2010;18:11-9.

61. Lee DW, Shim JC, Yang SJ, Cho SI, Kim JG. Functional effects of single semitendinosus tendon harvesting in anatomic anterior cruciate ligament reconstruction: comparison of single versus dual hamstring harvesting. Clin Orthop Surg 2019;11:60-72.

62. Sonnery-Cottet B, Daggett $M$, Helito $C P$, Fayard JM, Thaunat $M$. Combined anterior cruciate ligament and anterolateral ligament reconstruction. Arthrosc Tech 2016;5:e1253-e1259. 